\title{
Las candidaturas independientes en México: una experiencia paradójica
}

\author{
Independent Candidaturas in Mexico: A Paradoxical \\ Experience
}

JORGE FRANCISCO AGUIRRE SALA, MARCO ANTONIO ARANDA ANDRADE, JOSÉ MARÍA INFANTE BONFIGLIO y JOSÉ FABIÁN RUIZ

Universidad Autónoma de Nuevo León - Instituto de Investigaciones Sociales (México)

Artículo recibido: 26 enero 2017

Solicitud de revisión: 4 abril 2017

Artículo aceptado: 26 junio 2017

Resumen

El objetivo de este artículo es evaluar el desempeño democratizador de las candidaturas independientes en México a partir de su adopción en el año 2014. En específico, este trabajo analiza sus fundamentos jurídicos y sus requisitos legales y económicos en comparación con las candidaturas tradicionales de los candidatos de los partidos políticos. En la segunda parte del trabajo se analiza el desempeño de los candidatos independientes en los procesos electorales llevados a cabo en los años 2015, 2016 y 2017. Finalmente, se proponen algunas conclusiones que giran en torno a una cuestión central: a pesar de que las candidaturas independientes se introdujeron con la finalidad de estimular la participación ciudadana, han recibido poco apoyo electoral y, en general, han sido utilizadas de forma creciente por políticos vinculados a los partidos tradicionales que desean emprender una carrera política personal.

Palabras clave: candidaturas independientes, procesos electorales, democracia, México

\begin{abstract}
The aim this paper is to evaluate the performance of the independent candidates in Mexico, since its legal adoption in 2014. Specifically, this paper analyses its legal foundations, the legal and the economic requirements - compared to the traditional candidacies of the political parties. The second part of the paper analyses the performance of the independent candidates in the electoral processes carried out in the years 2015, 2016 and 2017. Finally, some conclusions are proposed that revolve around a central question: although the Independents candidacies were introduced with the aim of stimulating the citizen participation, they have received generally a minor electoral support, and they have been increa-
\end{abstract}


singly used by politicians linked to traditional parties who wish to begin a personal political career.

Keywords: Independent candidates, electoral process, democracy, Mexico.

\section{INTRODUCCIÓN}

La implementación de mecanismos para mejorar la calidad de la democracia en México es incipiente. Fue recién en la reforma del año 2012 que comenzaron a desarrollarse (Lissidini et al., 2008 y Lissidini et al., 2014). En efecto, con la reforma política del 9 de agosto de 2012 emergieron en el escenario democrático nuevas formas de participación política: la posibilidad de presentar iniciativas de leyes de origen ciudadano, las consultas populares vinculantes y las candidaturas independientes.

Las posteriores reformas del 10 de febrero de 2014 se caracterizaron por atender menos a los aspectos de la democracia participativa e incorporar nuevos elementos al modelo de la democracia representativa: se abrió la posibilidad de reelección a los representantes, se afinaron y ampliaron las condiciones para establecer un gobierno de coalición en el Congreso para evitar que algunas iniciativas presidenciales sean bloqueadas por oposiciones mayoritarias, se reguló el porcentaje mínimo de elección que deben obtener los partidos para conservar su registro, también se estableció un nuevo principio sobre la equidad de género entre candidatos, se dio reconocimiento jurídico a los usos y costumbres de gobierno representativo en las etnias indígenas, se estipuló de manera general la alternativa del voto electrónico para los conciudadanos residentes en el extranjero y se precisaron las condiciones para postular, registrar y ejecutar las candidaturas independientes.

A pesar de la sucesiva y novedosa alternancia en el poder - pues después de 75 años de dominio del Partido Revolucionario Institucional, el Partido Acción Nacional lo desplazó en el año 2000 y dos períodos presidenciales después, en el 2012, este fue desplazado por aquel- y las reformas políticas de una y otra parte, las figuras de democracia directa como el referéndum, el plebiscito, la revocatoria de mandato, el presupuesto participativo, la audiencia pública, la contraloría social, el derecho de petición, el derecho de reclamación y la afirmativa ficta, no se introdujeron en la Constitución nacional, aunque ya han sido incorporados en algunas constituciones estatales y en el ámbito municipal. 
Como la reforma política de 2014 no avanzó hacia la incorporación de instrumentos de democracia directa, recibió el adjetivo de «electoral» sin más, pues no generó una profunda reforma política (Aguirre, 2014). Es decir, fue sólo una reforma dentro del modelo democrático representativo y no se ahondó en las posibilidades de la democracia directa, deliberativa o con elementos mixtos de participación directa dentro de estructuras representativas.

Como señala Zovatto (2014: 24, 28, 48, 49), en México tienen reconocimiento jurídico los mecanismos directos de la iniciativa ciudadana y la consulta popular, y por ratificación del Convenio 169 de la Organización Internacional del Trabajo - aprobado en 1989-, la consulta previa a grupos indígenas. Pero estos mecanismos no se han utilizado a nivel nacional. No obstante, la figura de la candidatura independiente para postular aspirantes a puestos de elección en las instituciones representativas existe para todas las escalas de gobierno y por las condiciones de los períodos electorales se ha aplicado en todas ellas, a excepción de la candidatura a la presidencia de la república, que tendrá en 2018 la primera ocasión. Tal figura se halla en el artículo 35 de la Constitución que establece como derechos del ciudadano:

\footnotetext{
II. Poder ser votado para todos los cargos de elección popular, teniendo las calidades que establezca la ley. El derecho de solicitar el registro de candidatos ante la autoridad electoral corresponde a los partidos políticos así como a los ciudadanos que soliciten su registro de manera independiente y cumplan con los requisitos, condiciones y términos que determine la legislación.
}

Por ende, la candidatura independiente es la fórmula que, en las estipulaciones jurídicas y en sus experiencias incipientes, promete poner a México en el mapa de la renovación democrática de camino hacia un modelo representativo que empieza a desligarse del sistema de partidos. En ese sentido, las preguntas de investigación que pretende resolver este artículo son: a) ¿Las candidaturas independientes responden al objetivo de incrementar la calidad democrática lo suficiente para superar la desafección ciudadana causada por el sistema de partidos? b) ¿Qué tan equitativas son las condiciones jurídicas para una candidatura independiente, contrastadas con los requisitos impuestos a un partido político? c) ¿Cuáles son las ventajas y las desventajas democráticas de la postulación de un candidato independiente? $d$ ) ¿En qué sentido han reaccionado los gobernantes, los postulantes y los electores ante la novedad de la figura del candidato inde- 
pendiente en México en sus primeras experiencias de los años 2015, 2016 y 2017 ?

Como hipótesis, podríamos afirmar que las candidaturas independientes tienden a reforzar las tendencias oligárquicas y excluyentes del sistema político. Esto es así porque confluyen: 1) la necesidad de asignar los cargos públicos sin apoyo partidista, por lo que el independiente, en caso de alcanzar el poder, tendería a distribuirlos entre sus allegados y aquellos con quienes se comprometió durante el registro y la campaña electoral; 2) al no contar con apoyo de un partido en el parlamento, el independiente se vería orillado y empujado a buscar mecanismos que eviten o limiten el papel del Congreso en la implementación de la agenda gubernamental; 3) esto se refuerza ante la inexistencia de mecanismos que garanticen la reciprocidad - responsiveness- con su electorado.

A su vez, la falta de reciprocidad de los partidos acontece en un medio signado por la desafección política. Según el informe 2016 de Latinobarómetro, el $48 \%$ de los mexicanos apoya a la democracia, el $18 \%$ cree que se gobierna en beneficio del pueblo, en tanto el $76 \%$ cree que el gobierno está en manos de grupos poderosos que lo usan en su propio beneficio, el $25 \%$ aprueba el desempeño del gobierno, el $56 \%$ reconoce que ha perdido la credibilidad en la política y no la va a recuperar (Latinobarómetro, 2016).

Por lo tanto, la necesidad democratizadora es urgente ante las objeciones y limitaciones que genera el modelo representativo, pero no resulta solventada por los candidatos independientes a pesar de la movilización social que los apoyó en su emergencia a la arena política.Y ello es así porque también son sumergidos por la inercia del sistema partidista, «cuyo colapso en el atractivo y la credibilidad de la política representativa no se limita a la política oficial o sus principales procesos» (Tormey, 2015: 116).

El modelo representativo se enfrenta, según Manin (1997), a cuatro obstáculos: a) la forma de elegir a los representantes y las características personales que marcan su preferibilidad; $b$ ) el grado de autonomía otorgado a los representantes; $c$ ) las funciones e influencias de la opinión pública; y d) el espacio de la deliberación política.

Las dificultades inherentes a los mecanismos de representatividad y los criterios de elección resultarían banales si la organización de un gobierno democrático fuera mayormente participativa y esos aspectos se pudieran consensuar. El modo de elegir representantes y sus filiaciones doctrinales son nimios en comparación con la ausencia de políticas públicas generadas por consensos o prácticas deliberativas. Las verdaderas dificultades emanan de la autonomía de los representantes, pues esta genera una asime- 
tría de poder frente a sus representados. La representación de los gobernantes obedece a una representatividad fiduciaria (Bobbio, 1999; Rehfeld, 2009: 215) y no delegada, es decir, el representante posee libertad para actuar en nombre del representado y por tanto no tiene una representatividad vinculante ni la obligación de ejecutar mandatos, no tiene obligación de normar su parecer de conformidad con sus representados y, en consecuencia, no está sujeto a sanciones. Por lo tanto, «los partidos de gobierno han expropiado a los electores su influencia política» (Pasquino, 1988: 25) y han ejecutado un proceso de oligárquico y de burocratización conocida desde hace más de un siglo como la «ley de hierro» (Michels, 1915), por la cual los representantes son elegidos con métodos establecidos por ellos mismos, las elecciones se hacen sobre una lista cerrada de candidatos y, una vez instaurados, amplían las reglas de su oligarquía: el clientelismo, el patrimonialismo y el corporativismo. Los candidatos independientes, una vez electos, no pueden sustraerse del todo de la tendencia a la oligarquía y la inercia de la representatividad fiduciaria, a menos que adopten la modalidad de la democracia líquida (Aguirre, 2016).

De acuerdo con lo anterior, las candidaturas independientes podrían realizar tres aportes fundamentales a la democracia mexicana. En primer lugar, ofrecen un camino alternativo para que los ciudadanos, sin pasar -ni aceptar- por los mecanismos tradicionales de los partidos políticos, puedan aportar sus proyectos a la gestión pública, colaborando así a su renovación. En segundo lugar, pueden constituirse en mecanismos idóneos para que los ciudadanos desencantados reconstruyan un mecanismo de acercamiento a la política y sus instituciones. En tercer lugar, y como resultado de lo anterior, las candidaturas independientes pueden ayudar a superar la brecha entre ciudadanos e instituciones, relegitimando la acción política, en un contexto de inclusión ciudadana.

\section{EQUIDAD JURÍDICA ENTRE CANDIDATOS PARTIDISTAS Y CANDIDATOS INDEPENDIENTES}

Las condiciones para registrar a los candidatos independientes a la presidencia de la república, las senadurías y las diputaciones federales por mayoría relativa, se encuentran en la Ley General de Instituciones y Procedimientos Electorales (LGIPE). Los requisitos para los cargos de elección estatales - gubernatura, diputados estatales, presidentes municipales- son variables según la entidad federativa de que se trate y según el orden de 
gobierno al que se aspire. A diferencia del 0,26 por ciento del padrón electoral que requiere el registro de cualquier partido político (Art. 10, sección 2 , incisos b) y c) de la Ley general de partidos políticos, 2014) que podrá postular a sus candidatos, los requisitos para registrar candidatos independientes a la presidencia, senaduría y diputación federal son superiores. En la tabla n. ${ }^{\circ} 1$ pueden observarse las condiciones que deben cubrir los candidatos independientes para la escala federal.

Tabla 1

Requisitos para registrar candidatos independientes en la escala federal

\begin{tabular}{|c|c|c|c|}
\hline Requisito & Presidencia & Senaduría & Diputación federal \\
\hline $\begin{array}{l}\text { Firmas de apoyo del } \\
\text { padrón electoral }\end{array}$ & $\begin{array}{l}1 \% \text { distribuido en } \\
17 \text { estados }\end{array}$ & $2 \%$ & $2 \%$ \\
\hline $\begin{array}{l}\text { Tiempo de recolec- } \\
\text { ción }\end{array}$ & 120 días & 90 días & 60 días \\
\hline Suplencia & Prohibida & Prohibida & Prohibida \\
\hline Financiamiento & $\begin{array}{l}\text { Privado, con límite } \\
\text { al } 10 \% \text { de las cam- } \\
\text { pañas anteriores }\end{array}$ & $\begin{array}{l}\text { Privado, con límite } \\
\text { al } 10 \% \text { de las cam- } \\
\text { pañas anteriores }\end{array}$ & $\begin{array}{l}\text { Privado, con límite } \\
\text { al } 10 \% \text { de las cam- } \\
\text { pañas anteriores }\end{array}$ \\
\hline $\begin{array}{l}\text { Espacios en mass } \\
\text { media }\end{array}$ & Ninguno & Ninguno & Ninguno \\
\hline $\begin{array}{l}\text { Representación } \\
\text { territorial }\end{array}$ & En 17 estados & $\begin{array}{l}\text { En el } 50 \% \text { de los } \\
\text { distritos con el } 1 \% \\
\text { de electores en } \\
\text { cada uno }\end{array}$ & $\begin{array}{l}\text { En el } 50 \% \text { de los } \\
\text { distritos con el } 1 \% \\
\text { de electores en } \\
\text { cada uno }\end{array}$ \\
\hline
\end{tabular}

Fuente: Ley General de Instituciones y Procedimientos Electorales, 2014, México

En la tabla n. ${ }^{\circ} 2$ pueden observarse los requisitos de algunas entidades federativas para registrar a los candidatos independientes al cargo de gobernador. Cabe hacer hincapié en la diferencia entre el registro de un partido político, cuyos militantes han de sumar como mínimo el 0,26 por ciento del padrón electoral y los candidatos independientes. 
Tabla 2

Requisitos para registrar candidatos independientes en la escala estatal

\begin{tabular}{|c|c|c|c|c|}
\hline Requisitos & Quintana Roo & Durango & Zacatecas & Nuevo León \\
\hline $\begin{array}{l}\text { Firmas de } \\
\text { apoyo del pa- } \\
\text { drón electoral }\end{array}$ & $3 \%$ & $3 \%$ & $1 \%$ & $2 \%$ \\
\hline $\begin{array}{l}\text { Tiempo de } \\
\text { recolección }\end{array}$ & 19 días & 40 días & 40 días & 37 días \\
\hline Suplencia & Prohibida & Prohibida & Prohibida & Prohibida \\
\hline Financiamiento & $\begin{array}{l}\text { Privado, respe- } \\
\text { tando montos } \\
\text { permitidos a } \\
\text { partidos }\end{array}$ & $\begin{array}{l}\text { Privado, con } \\
\text { límite de } 10 \% \\
\text { respecto a } \\
\text { monto de cam- } \\
\text { pañas previas }\end{array}$ & $\begin{array}{l}\text { Privado, con } \\
\text { límite de } 10 \% \\
\text { respecto a } \\
\text { monto de cam- } \\
\text { pañas previas }\end{array}$ & $\begin{array}{l}\text { Privado, con } \\
\text { límite al } 50 \% \\
\text { de la elección } \\
\text { en turno }\end{array}$ \\
\hline $\begin{array}{l}\text { Espacios en } \\
\text { mass media }\end{array}$ & $\begin{array}{l}\text { No, al menos } \\
\text { de manera } \\
\text { directa (se } \\
\text { permiten entre- } \\
\text { vistas en me- } \\
\text { dios) }\end{array}$ & Ninguno & $\begin{array}{l}\text { No, al menos } \\
\text { de manera } \\
\text { directa (se } \\
\text { permiten entre- } \\
\text { vistas en me- } \\
\text { dios) }\end{array}$ & Ninguno \\
\hline $\begin{array}{l}\text { Representación } \\
\text { territorial }\end{array}$ & $\begin{array}{l}3 \% \text { distribuido } \\
\text { en la totalidad } \\
\text { de los distritos } \\
\text { de la entidad }\end{array}$ & $\begin{array}{l}3 \% \text { en por lo } \\
\text { menos en } 20 \\
\text { municipios que } \\
\text { sume cuanto } \\
\text { menos el } 2 \% \\
\text { de ciudadanos } \\
\text { inscritos en } \\
\text { cada uno }\end{array}$ & $\begin{array}{l}1 \% \text { de la lista } \\
\text { nominal en, } \\
\text { por lo menos, } \\
30 \text { municipios } \\
\text { o } 9 \text { distritos }\end{array}$ & $\begin{array}{l}\text { En } 26 \text { munici- } \\
\text { pios con el } 1 \% \\
\text { de cada distrito }\end{array}$ \\
\hline
\end{tabular}

Fuente: Organismos públicos locales y legislación electoral de cada estado

En el caso de algunos municipios, los porcentajes de apoyo a los candidatos independientes aumentan en relación inversa al número de electores, es decir, cuanto menor sea el tamaño del municipio, mayor deberá ser el número de quienes lo apoyen. Se trata, sin duda, de una curiosa lógica aritmética establecida para fortalecer la resistencia de los partidos políticos.

Respecto a la representatividad territorial, si se ilustra el caso con la aspiración a la presidencia de la república, las senadurías y las diputaciones 
por mayoría relativa, los electores que apoyen a un candidato independiente deben encontrarse al menos en la mitad de los distritos de su entidad, sumando, en esa mitad de distritos, un mínimo del uno por ciento de la lista nominal de electores (LGIPE, art. 371). Es decir, los aspirantes a candidatos independientes deben poseer una verdadera representatividad con extensión demográfica en su entidad porque no se validan los porcentajes solicitados por la ley si estos se obtienen condensados en pocas áreas. Esta condición no se impone a los candidatos de los partidos políticos, quienes pueden obtener su registro al margen de la expansión de la representatividad demográfica en sus distritos.

El plazo original para conseguir el apoyo ciudadano y lograr el registro como candidato independiente es muy limitado en general. Para el caso de la presidencia de la república -que requiere el uno por ciento de la lista nominal de electores en la mitad de la república- es de cuatro meses, para una senaduría es de tres meses y para las diputaciones federales es de dos meses entre la publicación de la convocatoria y el cierre del registro de aspiración. En contraste, los partidos políticos tienen dinámicas internas de elección para sus respectivos candidatos que solo están sujetas a la fecha límite del registro del candidato oficial.

A las dificultades de un menor plazo y un mayor número de electores y áreas de apoyo para lograr el registro de una candidatura independiente se suma la prohibición del uso de los medios masivos tradicionales de comunicación durante el proceso de previo al registro. Los candidatos independientes solo tendrán acceso a radio y televisión una vez registrados, no durante la época previa a la convocatoria o dentro del plazo para conseguir el registro de postulación (Art. 412, LGIPE).

Una vez obtenido el registro, las desventajas de los candidatos independientes frente a los candidatos de partidos políticos también son notorias. Un candidato independiente no podrá tener sustituto suplente, así que en caso de incapacidad sus esfuerzos participativos no obtendrán ningún fruto. Tampoco contará con un reparto equitativo del financiamiento público para las campañas, pues le corresponderá, la parte proporcional del 33,3 por ciento que se distribuya entre todos los candidatos independientes. Es decir, que si existiera un solo candidato independiente, este recibiría el 33,3 por ciento de apoyo oficial destinado a la campaña correspondiente a su puesto de elección, pero si fueran dos candidatos independientes en la misma contienda, a cada uno les correspondería el 16,6 por ciento y así, sucesivamente, a medida que existieran más candidatos independientes, disminuiría el porcentaje de apoyo financiero (Art. 408, LGIPE). Por otra par- 
te, el financiamiento de origen privado que pudiera obtener solo podrá sumarse, previa autorización del Tribunal Electoral del Poder Judicial de la Federación, con el apoyo público hasta alcanzar, como máximo posible, el 10 por ciento de tope de gasto para la elección de que se trate (Art. 399, LGIPE) o el $50 \%$ de tope de gasto de campaña.

En lo referente al material para emitir el voto, al candidato independiente le está prohibido el uso de su fotografía en la boleta electoral (Art. 434, LGIPE). Por tanto, deberá usar un logo que puede confundirse con algún partido nuevo o de poca representatividad y no tiene oportunidad de asociar la imagen personal utilizada durante la campaña electoral con el espacio gráfico que le corresponde en la boleta de votación.

En definitiva, dados los requisitos legales que sujetan a las candidaturas independientes, puede decirse que aun cuando no se hizo público el argumento principal, es claro que se trataba de dificultar al máximo a las candidaturas independientes, al establecer obstáculos e impedimentos adicionales.

No obstante, partidos políticos y candidatos independientes se encuentran en la modalidad democrática representativa. A efecto de hacer notoria la menor democratización por parte de esta figura y de afectar la calidad de la democracia, cabe destacar que una vez electos, la concentración del poder es mayor en la figura del independiente. Ello se evidencia en la composición de los puestos centrales del poder ejecutivo del Estado, donde la designaciones hechas por el gobernador se basarán en relaciones particularistas y no en una selección dentro de un grupo partidario. Sin embargo, en ambas modalidades persiste el problema de los electores que quedan sujetos a la representación fiduciaria. Representación que Pitkin denominó «por autorización» en un texto fundacional sobre el tema (1972) y que tras treinta y dos años de estudios y debates evaluó sentenciando: «el resultado predominante ha sido que la representación ha suplantado a la democracia en lugar de servirla» (2004: 340).

\section{VENTAJAS Y DESVENTAJAS DEMOCRÁTICAS DE LAS CANDIDATURAS INDEPENDIENTES}

Las candidaturas independientes fueron promovidas para fomentar una mayor representatividad de todos los sectores ciudadanos, una mayor apertura del espectro político y mayor calidad de la responsiveness, tal y como lo registran los debates parlamentarios a partir de la propuesta del presi- 
dente Felipe Calderón del 15 de diciembre de 2009, que contempló las candidaturas independientes para todos los cargos de elección popular, incluidos los municipales. En el debate a dicha iniciativa, el grupo parlamentario del Partido de la Revolución Democrática, del Partido del Trabajo y del partido Convergencia, en voz del senador Arturo Núñez, presentó el 18 de febrero de 2010 la iniciativa de los independientes solo para presidente de la República, senadores y diputados federales. Por su parte, el Partido Verde Ecologista Mexicano, por intermediación del senador Arturo Escobar, el 4 de marzo de 2010 impulsó la iniciativa de independientes solo para la elección de 32 diputados de mayoría. Las iniciativas para promover las candidaturas independientes también tenían en cuenta de la mala experiencia iniciada desde 1977 y cerrada en 1996 para ampliar el espectro político dando oportunidad a nuevos partidos minoritarios que, por desgracia, no lograron mantener su registro (Arellano, 2015:8). En el Dictamen de las Comisiones Unidas de Puntos Constitucionales (Senado de la República, 2011: 40) respecto a los independientes se declaró:

\begin{abstract}
las candidaturas independientes deben ser una fórmula de acceso a ciudadanos sin partido para competir en procesos comiciales, no una vía para la promoción de intereses personales o de poderes fácticos que atenten contra la democracia y el propio sistema electoral y de partidos políticos. Estos últimos deben seguir siendo la columna vertebral de la participación ciudadana, los espacios naturales para el agrupamiento y cohesión de la diversidad que está presente en la sociedad, de forma tal que la diversidad encuentra en ellos un cauce democrático para dar lugar a la pluralidad de opciones que compiten por el voto ciudadano y hacen posible el acceso de los ciudadanos al ejercicio de los cargos públicos de elección popular.
\end{abstract}

Con esa declaración quedaba claro que el propósito de las candidaturas independientes es obtener un espacio gubernamental por vía de la elección dentro de la modalidad representativa, al margen del poder de los partidos políticos. Su emergencia en la arena política, en parte también nació de la insatisfacción con el desempeño de los representantes políticos que están más sujetos a los compromisos con el partido que los llevó a la postulación que con los votantes, quienes los encumbraron en la victoria electoral.

Otra razón que generó en México la aparición de la figura del candidato independiente corresponde a las movilizaciones civiles en torno al voto nulo (Arellano, 2015). El abstencionismo posee varias circunstancias y, por ende, efectos múltiples. Si una cantidad significativa de simpatizantes a un partido determinado se abstienen porque consideran que las encuestas indican su victoria y consideran innecesario acudir a votar, pueden perder 
las elecciones. Si el abstencionismo es coordinado o motivado soterradamente al promover la indiferencia política de la ciudadanía, entonces deja libre el camino del triunfo electoral al partido político que consiga la mayoría simple o relativa. Dado que en México no existe la figura de balotaje o segunda vuelta electoral para garantizar que el ganador de una elección posea legitimidad gracias a la mayoría absoluta, el abstencionismo coordinado es indeseable. Por su parte, el abstencionismo no coordinado no favorece a nadie, pues su resultado final es aleatorio. En cualquier caso, las estrategias y resultados del abstencionismo o voto nulo no favorecen la representación.

Al buscar en los candidatos independientes la fórmula para evitar el abstencionismo al dar cauce a más posibilidades de representación ciudadana y la liberación de las consignas partidistas, se pretendió incrementar la democratización y otorgar cabida a la participación. Al ampliar candidatos más allá de los partidos posiblemente se amplíe el espectro ideológico desde donde se pretenden definir ampliamente las políticas públicas para el caso del poder legislativo. También destaca la apertura al poder de nuevos actores políticos que abonan experiencia, inclusión y probidad. La incorporación gubernamental de las fuentes políticas y sociales que respaldan las candidaturas independientes también significa el posible contrapeso a la hegemonía oligárquica de los partidos políticos, sobre todo en la realidad mexicana que, como se ha dicho, tuvo durante 75 años a un partido único en el poder. Aunque la oligarquía en el poder ejecutivo de un candidato independiente ganador es más centralizada que la de los partidos, puesto que no posee los compromisos partidarios.

El contrapeso a la hegemonía partidista puede consolidarse cuando el descontento con los ordenamientos prevalecientes se traslada de las movilizaciones sociales a las instituciones y estas logran satisfacer las demandas ciudadanas. Pero si las instituciones se encuentran cooptadas por los partidos políticos, entonces las candidaturas independientes constituirían la vía regia para renovarlas y adaptarlas a los retos de la responsiveness, es decir, a la reciprocidad entre los deseos de los ciudadanos y las actuaciones de sus representantes.

Quizá la pretensión de democratización más significativa de las candidaturas independientes sea la institucionalización de la movilización ciudadana - con sus demandas y respaldo legitimador- en las condiciones de certidumbre política que alcanzará la materialización de nuevos ordenamientos deseables. 
Ahora bien, la institucionalización de los movimientos y movilizaciones sociales, así como la canalización representativa de nuevos proyectos de organización y ejecución, son vulnerables a la ritualización y, precisamente, a la cooptación procedimental. En palabras más sintéticas, como ha indicado Woldenberg (2012), los candidatos independientes terminarán siendo, inevitablemente, partidos políticos en sí mismos. Ello porque, estrictamente hablando, las candidaturas independientes - aún con la autonomía y la distancia que tienen de los partidos- no deben ni pueden concebirse como un instrumento del modelo de democracia directa.

Las razones de las desventajas democráticas de las candidaturas independientes son variadas: desde las limitaciones comunicativas, pasando por la inercia parlamentaria en el caso del poder legislativo, hasta la ausencia de alianzas políticas con los partidos del poder legislativo para los funcionarios del poder ejecutivo.

El independiente ganador en el poder legislativo se enfrenta con desventaja a la inercia del modelo representativo y de los partidos políticos. En el diario proceder de las cámaras, los tiempos de las agendas políticas y la complejidad de sus asuntos no permiten al candidato independiente - que carece del respaldo estructural de un partido para estar permanentemente presente ante su electorado- superar las limitaciones comunicativas con los ciudadanos que representa. Difícilmente el independiente elegido tendrá oportunidad para disponer de su curul en el sentido que esperarían los ciudadanos de su distrito político. Esta responsabilidad conlleva algunas dificultades prácticas: $a$ ) ¿con qué método precisar la política que goza de la preferencia mayoritaria dentro de la multiplicidad de un electorado heterogéneo?; $b$ ) ¿cómo evitar la tiranía de las mayorías al seguir las preferencias mayoritarias o de las elites representativas que suplantan a las mayorías?; c) ¿de qué manera fincar la responsabilidad en el electorado cuando se han canalizado sus preferencias de manera adecuada y éstas no dieron el resultado esperado?, y $d$ ) ¿cómo evitar la pérdida de credibilidad si la política designada por los gobernantes no resultó técnica o financieramente viable? Esta desventaja democrática obedece, precisamente, a la tara del modelo representativo que también hiere a la figura del independiente. En consecuencia, en tanto que miembro de un sistema de representantes, requiere transitar hacia la modalidad de la democracia líquida en los términos de auto-concebirse como un apoderado proxy, es decir, como un delegado y no un representante fiduciario (Aguirre, 2016: 107).

En el caso del independiente ganador para un puesto en el poder ejecutivo, la ausencia de alianzas representaría la mayor desventaja política. Un 
gobierno ejecutivo encabezado por un independiente tendría muy poco margen de maniobra cuando su contraparte legislativa está en manos de los partidos políticos a quienes desplazó en el poder. La disyuntiva hacia la fidelidad de intereses sería radical: los partidos en el legislativo con quienes necesitarían negociar o el electorado. Las experiencias mundiales de presidentes o gobernadores cuya filiación política es minoría en los congresos muestran el poco margen de gobernabilidad. Para un candidato independiente dicho margen quedaría reducido a las prerrogativas que le otorga la ley y, más allá de estas, su gobernabilidad estaría condicionada.

En la teoría, el balance democrático entre pros y contras de las candidaturas independientes es todavía incierto. Las variables legales en cada región y escala de gobierno apuntan a un balance desfavorable. Toca el turno de analizar las prácticas políticas en México para validar estas afirmaciones y la hipótesis sobre los resultados no democratizadores.

\section{REACCIONES POLÍTICAS RESPECTO A LAS CANDIDATURAS INDEPENDIENTES}

\subsection{El desempeño de los candidatos independientes}

En el año 2015 se realizaron elecciones federales para renovar el Congreso. Además, en 17 entidades se realizaron elecciones para seleccionar distintas autoridades locales - legislaturas estatales, ayuntamientos- y en nueve de ellas se eligió al gobernador. Para cubrir estos puestos, tanto federales como locales, además de los candidatos partidistas, lograron registrarse como candidatos 134 independientes. Como candidatos a gobernador solo alcanzaron el registro efectivo 3, de los cuales solo ganó Rodríguez Calderón, «el bronco», en Nuevo León. Además, para las alcaldías solo 3 consiguieron la victoria. Hubo 29 que se registraron como candidatos a diputados locales, de los que fue elegido solo 1. Finalmente, 22 independientes se registraron como candidatos a diputados federales, siendo elegido 1. En total, 6 candidatos independientes fueron elegidos, lo que representó el 4,47 por ciento del total de independientes registrados (Cantú, 2015; Castro, 2017).

En esa elección, el 73 por ciento de los candidatos independientes obtuvieron menos del 10 por ciento de los votos de su distrito o circunscripción, el 17 por ciento consiguió entre 10 y 20 por ciento de adhesiones y solo 1 de cada 10 candidatos obtuvo más del 20 por ciento de los votos. 
Más aún: los independientes con mejor desempeño electoral se ubicaron en las entidades que presentaron el mayor número de candidaturas independientes -Nuevo León, Sinaloa y Michoacán (Arellano, 2015:18).

En el año 2016 se realizaron elecciones locales en 12 entidades federativas en distintos niveles, además de la elección a constituyentes para la Asamblea Constituyente de la Ciudad de México. La cantidad de postulaciones independientes se incrementó, no así el éxito electoral que estos alcanzaron. En efecto, se registraron 308 candidatos independientes, resultando ganadores solo 10 de ellos (Castro, 2017). En 12 entidades, además se renovó al gobernador estatal, anotándose candidatos independientes en 9 de ellas. Los resultados para los independientes incluyeron 10 victorias: 9 ganaron la titularidad de distintas alcaldías del país, y 1 fue elegido como representante en la Asamblea Constituyente de la Ciudad de México, en la cual la participación electoral cayó a un mínimo histórico de 29 por ciento. En total, fueron elegidos el 3,2 por ciento de los independientes contra el 4,47 por ciento del año 2015. Más aún: en los nueve estados en que se registraron independientes como candidatos a gobernador, estos obtuvieron en total el 3,06 por ciento de los votos - contra el 2,31 por ciento de votos nulos y por candidatos no registrados. A su vez, en las entidades donde se registraron independientes como candidatos a diputados locales, obtuvieron el 1,01 por ciento de la votación - por oposición al 2,95 por ciento que sumaron los votos nulos y los candidatos no registrados (Torres, 2016). Entre las causas de estas bajas adhesiones se señalan el escaso financiamiento público, más los impedimentos para acceder a los espacios en radio y televisión (Torres, 2016).

Otro aspecto destacable en la elección de 2016 fueron los aspirantes independientes a gobernador: más de la mitad tenían afiliación partidista previa -incluso, algunos en más de dos partidos distintos. Ahora bien, ¿interfiere este origen partidista en el desempeño electoral de los candidatos independientes?

Podría suponerse que en la medida que la afiliación partidista permitió el acceso a cargos públicos, y con ellos a los medios de comunicación, el origen podría otorgar popularidad y reconocimiento al candidato. Sin embargo, si se atienden los resultados electorales de las doce entidades que eligieron gobernador en el año 2016, se observa que tal suposición resulta equivocada. Solo uno de los candidatos independientes, José Luis Barraza González, en Chihuahua, logró atraer el 18,21 por ciento de las preferencias. El resto de los candidatos independientes se ubicaron por debajo del 4 por ciento de los votos. Por otra parte, Barraza González era uno de los 
candidatos que no tenían militancia política ni había ocupado previamente puestos públicos. En cambio, los candidatos independientes que mejor se posicionaron, en los casos de Puebla, Sinaloa, Aguascalientes, Veracruz, Durango y Tamaulipas, ya habían tenido militancia en alguno de los tres partidos más grandes del país, cuando no en dos de ellos. Solo se diferencian del grupo los candidatos de Zacatecas y Tlaxcala: los del primer estado - dos candidatos independientes - sin experiencia previa y el de Tlaxcala, con activismo sindical en el Sindicato Nacional de Trabajadores de la Educación SNTE (Integralia, 2016a, 2016b y 2016c).

En las elecciones del año 2017, donde se eligieron gobernadores en tres entidades - estado de México, Coahuila y Nayarit-, además de elecciones municipales en Veracruz, se registraron 142 candidatos independientes, de los cuales parecen haber resultado ganadores 3 (Castro, 2017). Sin embargo, la cercanía del proceso electoral al momento de redactar este trabajo, y el hecho de que aún no se cuenta con los cómputos oficiales y definitivos de dicho proceso electoral, impiden avanzar en el análisis. En la tabla n. 3 puede observarse el desempeño electoral de los candidatos independientes mexicanos del período 2015 al 2017.

Al comparar las experiencias de 2015, 2016 y 2017, es destacable el caso de Jaime Rodríguez Calderón El Bronco. Sus 33 años de trayectoria en el PRI parecen no haberle afectado como candidato independiente en 2015 , a diferencia de sus homólogos de 2016 cuyo pasado partidista decididamente no los favoreció. De hecho, podría decirse que la experiencia partidista resultó benéfica para Rodríguez Calderón porque en 2017 la capitalizó en la creación del Consejo Estatal Independiente, AC y del Consenso Ciudadano Independiente, ambas como organizaciones no gubernamentales con estructuras, dinámicas y metas para funcionar como apoyos equivalente a su partido político privado. Ello, probablemente con miras a las elecciones del 2018.

En referencia a aspectos no electorales, como el deseo de desplazar a las candidaturas partidistas, es por demás significativo el pasado partidista de la mayoría de los candidatos independientes que, insístase, buscan la postulación por cuenta propia o como efecto de la marginación de su propio partido de origen. Esto es acorde con la tendencia europea señalada por Tormey; durante el último medio siglo se ha dado una precipitada disminución de la membresía a los partidos políticos, pues si bien eran capaces de atraer al 30 por ciento de la población votante, en la actualidad esa cifra a menudo es inferior al 10 por ciento (2015: 114). 
Tabla 3

Desempeño electoral de los candidatos independientes en México, 2015-2017

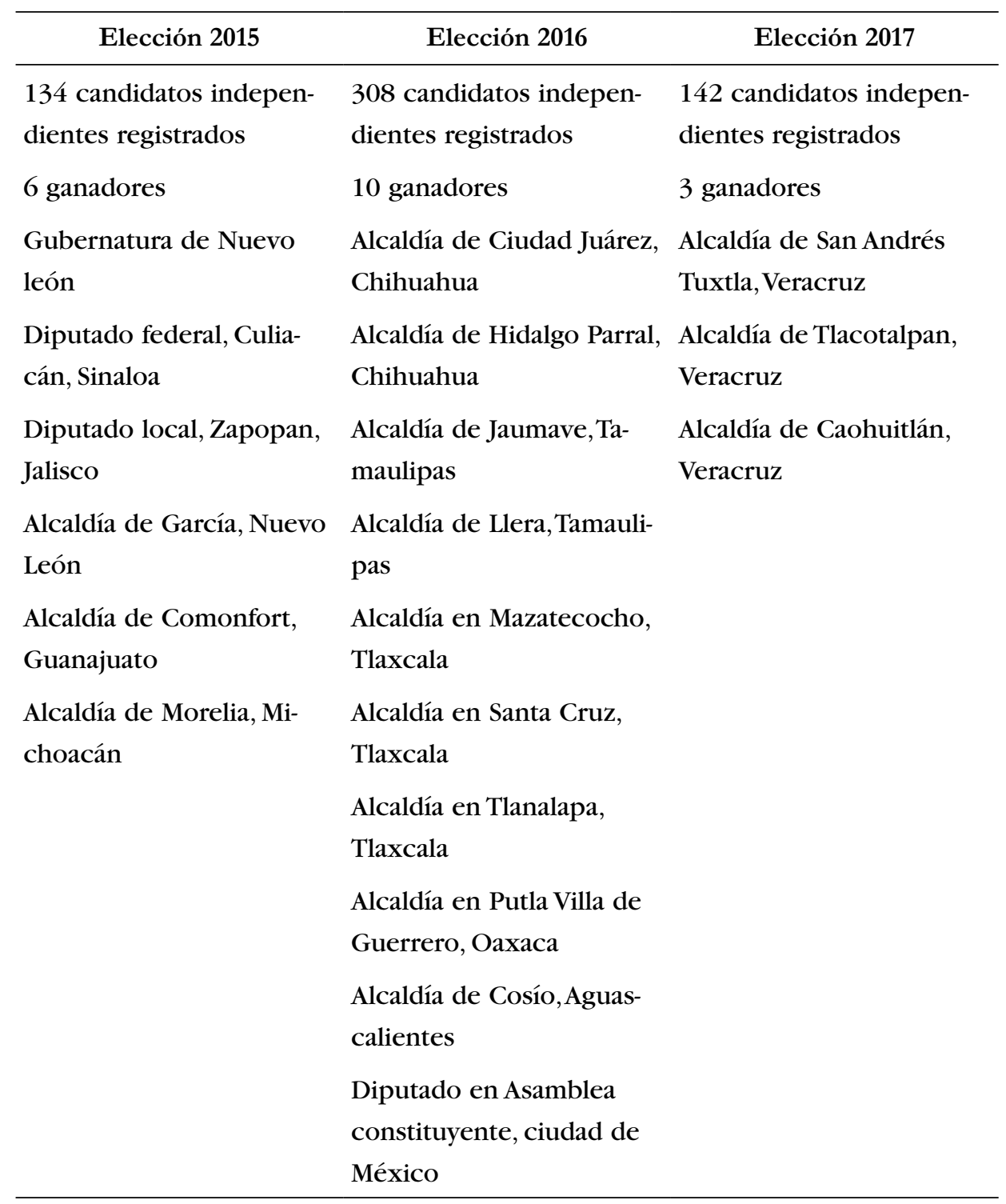

Fuente:Tomado de Castro (2017: 5) 
De igual manera, respecto al impacto en el sistema político es llamativa la actuación del diputado independiente en el estado de Jalisco, Pedro Kumamoto. El joven diputado, sin antecedentes partidistas y con una campaña electoral hecha por redes sociales cibernéticas, ha presentado al Congreso de la Unión la propuesta denominada con la expresión cibernética: \#sinvotonobaydinero. El lenguaje político adopta expresiones de las tecnologías de la información y la comunicación y apunta a ganar adeptos mientras alcanza popularidad. La iniciativa \#sinvotonobaydinero también ha sido avalada por el ahora diputado federal independiente Manuel Clouthier y tres congresos estatales, donde el de Nuevo León manifestó su apoyo por unanimidad a solicitud de Jorge Alán Blanco Durán, quien fuera diputado por el partido Movimiento Ciudadano y habiendo renunciado, ahora es del grupo de los independientes.

La iniciativa \#sinvotonobaydinero nace, precisamente, del desencanto y desconfianza de los electores por los partidos políticos. Esta iniciativa impacta en el financiamiento público que reciben los partidos desde 1997 y busca condicionárselo a sus propios méritos. \#sinvotonobaydinero pretende cambiar el modo y la razón de asignación de recursos a los partidos pasando desde una fórmula donde se les otorga una unidad de recurso por cada ciudadano registrado en la lista nominal electoral hacia una fórmula donde la unidad de recurso se establece por cada voto efectivo emitido en la anterior elección. Es decir, los partidos recibirán financiamiento variable en razón del número de ciudadanos que hayan ejercido el sufragio y no por la cantidad que conformen la lista del padrón electoral. Esto premia o castiga a los partidos políticos según el electorado acuda o no a votar o, en su defecto, los castiga cuando existen votos nulos o para candidatos no registrados. En el nuevo esquema, el 33,3 por ciento original que corresponde distribuir entre todos los independientes también se vería afectado en su monto.

\subsection{Reacciones de los gobernantes}

En México existieron postulaciones y casos efectivos de candidatos independientes de manera aislada; estos fueron anteriores a la reforma constitucional y política referida del 2014. El año 2015 fue el primero en la agenda política para aplicar esta figura, aunque el turno para presidente de la república está en la agenda del 2018. 
De entre los candidatos independientes a gobernador, Jaime Heliodoro Rodríguez Calderón El Bronco ganó la gubernatura de Nuevo León, obteniendo el 48,8 por ciento de las adhesiones. Su caso resulta interesante, ya que Rodríguez Calderón fue militante del Partido Revolucionario Institucional durante 33 años, tiempo en el que ocupó puestos destacados como diputado local, diputado federal y alcalde de García, Nuevo León, renunciando a su afiliación en septiembre de 2014 para presentar su candidatura independiente (Arellano, 2015: 20).

En la misma contienda electoral, paralelamente a los candidatos independientes, también se presentaron por primera vez, tres nuevos partidos políticos: Movimiento de Reconstrucción Nacional, un grupo escindido del Partido de la Revolución Democrática, que consiguió el 8,39 por ciento de las preferencias; Movimiento Ciudadano, que obtuvo el 6,09 por ciento, y el Partido Humanista, que recibió el 2,14 por ciento de la votación. Este hecho, sumado al surgimiento de las candidaturas independientes, refuerza un fenómeno sobre el que se insiste de forma reiterada: la insatisfacción ciudadana respecto de los partidos tradicionales (Ruiz, 2016).

Las reacciones del aparato gubernamental después de la experiencia del 2015 se acentuaron en la oligarquía partidista. Para estas reacciones, la prensa utilizó la denominación «ley(es) antibronco», debido al sobrenombre con que es conocido popularmente Jaime Heliodoro Rodríguez Calderón - El Bronco- desde su campaña electoral para la gubernatura de Nuevo León. El Bronco ganó por encima de la candidata del partido oficial en el poder, que había formado una coalición con otros tres partidos, y por encima del otro partido mayoritario. La explicación de esa victoria ha sido objeto de varios análisis políticos y el común denominador entre ellos es la superación del bipartidismo por parte de una ciudadanía desilusionada de los partidos políticos. Destaca, notoriamente, que los candidatos oficiales tuvieron más de dos mil spots en televisión y ocho mil en radio, mientras el candidato independiente tuvo menos de cien spots al sumar sus apariciones en televisión y radio, pues el núcleo de su campaña estuvo en las redes sociales cibernéticas.

Por ello, la reacción fue la construcción de obstáculos para los futuros candidatos independientes, de ahí la denominación «leyes antibronco». Por ejemplo, mientras en 2015 una candidatura a gubernatura estatal requería el 2 por ciento de firmas de la lista nominal de electores, a partir del 2016 en los estados de Puebla, Veracruz, Tlaxcala, Durango, Quintana Roo, Chihuahua y Tamaulipas el porcentaje se incrementó al 3 por ciento de la lista nominal. De igual manera, los plazos para cumplir con el registro se modi- 
ficaron: originalmente se establecieron en 60 días para la mayoría de las entidades federativas, mientras que a partir de 2015 Quintana Roo estipuló 19 días; Puebla, 30 días; Aguascalientes, Durango, Sinaloa, Tamaulipas, Tlaxcala y Zacatecas otorgan 40 días; y Chihuahua, 45 días. Al recorte de plazo se añade la prohibición de realizar precampañas para el registro.

Los requisitos para el registro también se endurecieron. Ello dio pauta a controversias legales que se presentaron ante la Suprema Corte de Justicia, pues algunas entidades federativas solicitaban que las firmas de apoyo estuvieran cotejadas con el padrón electoral, mientras otras exigían copia fotostática de la identificación oficial de elector más un comprobante de domicilio actualizado. De igual manera, algunas entidades requirieron que los candidatos independientes no hubieran participado en elecciones previas por parte de algún partido político y también se intentó una regulación muy severa sobre el uso de las redes sociales cibernéticas.

\section{CONCLUSIONES}

La experiencia de las candidaturas independientes en México revela hechos significativos que permiten considerar que dicha fórmula todavía resulta insuficiente para acercarse a modalidades alternativas deseables dentro de la democracia representativa. Una primera evidencia surge de las condiciones inequitativas de la competencia electoral entre los candidatos de partidos políticos y los candidatos independientes. Los requisitos de tiempo, formas de postulación y registro que deben satisfacer los candidatos independientes presentan grados de dificultad mayores a los requisitos establecidos para los candidatos de los partidos políticos.

En lo concerniente a los aspectos financieros, durante la contienda electoral, también existe una clara desventaja para los candidatos independientes, pues, como se ha citado, el máximo de financiamiento para los independientes constituye un porcentaje significativamente pequeño comparado con el apoyo que reciben los partidos y, además, debe ser dividido entre todos los postulantes independientes. El argumento principal, como se ha dicho, no se hizo público pero es claro: dificultar al máximo a las candidaturas independientes, al establecer obstáculos e impedimentos adicionales. De igual manera, para completar la respuesta sobre la equidad, cabe destacar que el acceso a medios masivos de comunicación se encuentra mucho más restringido para los candidatos independientes por las re- 
gulaciones legales. Por ello, la política de los independientes se está trasladando a las redes sociales cibernéticas.

No obstante, ante la tercera cuestión sustantiva de esta investigación, ¿cuáles son las ventajas y las desventajas democráticas de la postulación de un candidato independiente? Se sostiene que la existencia de candidatos independientes debería redundar en un mayor número de ventajas para la democracia, aun considerando de manera marginal las dificultades de tiempo, formas, financiamiento y procedimientos que deben superar los candidatos independientes por encima de los candidatos partidistas. La cuestión se enfoca, más allá de los requisitos y procedimientos, en la democratización de la democracia, en empoderar al posible ciudadano apartidista en una candidatura viable.

Al menos para el legislativo, los independientes ganadores tienen mayor oportunidad de adecuar su actuación con las preferencias, demandas y solicitudes de sus electores. Es decir, son más libres para responder al deseo de los representados - responsiveness-, pues no están sujetos a funcionar de manera clientelar u oligárquica por las consignas de pertenencia a un partido. Aunque, por otra parte, en los hechos se enfrentan a bloques y coaliciones de partidos. Por tanto, estrictamente considerado, no hay un mecanismo que asegure su responsiveness más allá de una probable reelección. Para asegurar la capacidad de respuesta a la voluntad popular se requeriría - en cualquier tipo de representante- del referéndum y del plebiscito.

En términos democráticos, el triunfo de un candidato independiente en el poder ejecutivo - a nivel nacional, estatal o local- tiene una doble implicación: por una parte, el ganador tendrá que asignar el resto de los cargos públicos entre su círculo de confianza. Con ello, la oligarquía que correspondía a los partidos políticos se vería todavía más centralizada en la oligarquía personalizada del candidato independiente triunfador. El independiente en el poder ejecutivo carece de compromisos partidistas, pero dichos compromisos los posee con quienes colaboraron para llevarlo al triunfo y/o con quienes ejercen los poderes fácticos en la arena política. Por otra parte, el independiente ganador en el ejecutivo se ve en mayor necesidad, y por ello mismo con menores márgenes de negociación, de establecer consensos con la contraparte de los miembros de poder legislativo y judicial. Aunque en el poder legislativo también existan representantes políticos provenientes de candidaturas independientes, ello no garantiza que entre los diversos independientes exista una lógica compartida como de suyo tienen los partidos políticos. 
Para responder a la cuarta cuestión de los objetivos planteados, lo relativo a las reacciones de los postulantes y los electores ante la novedad de la figura del candidato independiente, los procesos electorales de los años 2015,2016 y 2017 muestran que todavía no cabe considerar conclusiones firmes sobre el tema, pero permiten vislumbrar algunas premisas de análisis para futuras elecciones.

En primer lugar, se advierte un incremento de candidaturas independientes en proporción a los cargos de elección, por lo que, a pesar de las barreras y obstáculos impuestos al registro de tales candidaturas, parecen resultar una opción atractiva para quienes desean competir en la arena electoral.

En segundo lugar, es evidente que un número significativo de candidatos independientes presenta una trayectoria política partidista previa, lo que permite suponer que tales candidaturas constituyen una alternativa para quienes no pueden o no desean lograr la nominación por los canales convencionales. En efecto, esta es una tendencia contemporánea en el asunto principal de la política representativa, pues se observa esta conducta como «individualización o personalización, es decir, el comportamiento por el cual los sujetos se perciben a sí mismos como los autores de su propio destino en contraste al hallarse atados al destino colectivo de una identidad o grupo. Aunque no deja de ser parte del imaginario moderno» (Tormey, 2015: 118).

En tercer lugar, el apoyo electoral a tales candidaturas es aún escaso. Esto abre una duda a la mayor adhesión electoral en el futuro a medida que esta práctica se consolide y sea percibida como habitual. O, en su defecto, a pesar de todas las admoniciones en contra de los partidos políticos, estos seguirán liderando los procesos de selección de autoridades.

En cuarto lugar, los independientes enfrentan resistencias notables ante las consignas de los partidos, mucho más difíciles de sortear entre los independientes ejecutivos que entre los legislativos.

Por todo lo anterior, se produce una clara contraposición entre teoría y práctica, que deja como resultado una paradoja a destacar: si las candidaturas independientes fueron establecidas para estimular la participación política de los ciudadanos desafectos, al tiempo que permiten el surgimiento de nuevos liderazgos políticos allende a los partidos, sin embargo, la realidad hasta el momento comprueba lo contrario. No solo las candidaturas independientes han obtenido una escasa adhesión electoral -salvo casos puntualísimos-, sino que además fueron utilizadas por parte de políticos, vinculados en el pasado a los partidos, para iniciar una carrera al margen 
de los partidos, o que directamente no fueron candidateados. Es decir, los políticos tradicionales se valieron en buena medida de tales candidaturas para continuar sus carreras sin el amparo partidista. Para decirlo en sentido inverso al sabio refrán popular, las candidaturas independientes hasta el momento son - en contraste con el ideal deseable de una democracia más ciudadana- vino viejo en odres nuevos.

\section{REFERENCIAS BIBLIOGRÁFICAS}

Aguirre, J. (2014): «Un balance de las Reformas Políticas mexicanas 20122014 en el marco de las dificultades democráticas representativas superables por la democracia participativa en su versión electrónica», Escritos Sociológicos, Año 8, n. ${ }^{\circ} 12$ y 13, pp. 35-41.

- (2016): La democracia líquida. Los nuevos modelos políticos en la era digital, Barcelona, Universitat Oberta de Catalunya.

Arellano, E. (2015): Origen y balance de las candidaturas independientes, Ciudad de México, Centro de Estudios Sociales y de Opinión Pública, H. Cámara de Diputados.

Bobbio, N. (1999): «Rappresentanza e interessi», en Bovero, M. (ed.) (1999): Teoria Generale della politica, Torino, Einaudi.

Cantú, J. (2015): «Los independientes: quién es quién», Proceso, 18-06-2015 [http://www.proceso.com.mx/407911/407911-los-independientesquien-es-quien]

Castro, J. (2017): «Se extingue la llama independiente», El Horizonte, 06-062017.

Constitución De Los Estados Unidos Mexicanos, consultada el 16-05-2017 en https://www.juridicas.unam.mx/legislacion/ordenamiento/constitucion-politica-de-los-estados-unidos-mexicanos\#10573

INTEGRALIA (2016): Reporte Electoral Integralia. Disponible en: http://www. integralia.com.mx/content/publicaciones/018/Reporte\%20Electoral\%20Integralia\%202\%20(marzo\%202016).pdf

- (2016a): Reporte Electoral Integralia. Número uno. 21 de febrero de 2016, consultado el 11/01/2017. Disponible en: http://integralia.com. $\mathrm{mx} /$ content/publicaciones/017/Reporte\%20Electoral\%20Integralia $\% 20$ 2016-1\%20(21-02-2016).pdf

- (2016b): Segundo Reporte Electoral Integralia. 6 de marzo de 2016, consultado el 11/01/2017. Disponible en: http://integralia.com.mx/con- 
tent/publicaciones/018/Reporte\%20Electoral\%20Integralia $\% 202 \% 20$ (marzo\%202016).pdf

- (2016c): Quinto Reporte Electoral Integralia. 12 de junio de 2016, consultado el 11/01/2017. Disponible en: http://integralia.com.mx/content/publicaciones/022/Quinto\%20Reporte\%20Electoral\%20Integralia\%20(12-06-2016).pdf

LATINOBARÓMETRo (2016): Informe 2016, en Corporación Latinobarómetro, consultado el 07/06/2017. Disponible en: file:///C:/Users/Invest2/ Downloads/F00005843-Informe_LB_2016.pdf

Ley General de Instituciones y Procedimientos Electorales (lgipe) (2014): Diario Oficial de la Federación, Tomo DCXXVIII, n. ${ }^{\circ}$ 18. México, Secretaría de Gobernación.

Lissidini,A., Welp, Y. y Zovatto, D. (2008): Democracia directa en Latinoamérica, Buenos Aires, Prometeo Libros.

Lissidin, A., Welp, Y. y Zovatto, D. (2014): Democracias en movimiento. Mecanismos de democracia directa y participativa en América Latina, México, Universidad Nacional Autónoma de México.

Manin, B. (1997): The Principles of Representative Government, Cambridge, Cambridge University Press.

Michels, R. (1915): Political Parties. A sociological study of the oligarchical tendencies of modern democracy, New York, Hearst's International Library Co.

Pasquino, G. (1998): Shaping a Better Republic? The Italian Case in a Comparative Perspective, Madrid, Instituto Juan March de Estudios en Investigaciones.

PITKIN, H. (1972): The concept of representation, usA, Berkeley and Los Angeles, University of California Press.

- (2004): «Representation and Democracy: Uneasy Alliance», Scandinavian Political Studies, 27 (3), pp. 335-342.

RehfeLd, A. (2009): «Representation Rethought: On Trustees, Delegates, and

Gyroscopes in the Study of Political Representation and Democracy», The American Political Science Review, 103 (2), pp. 214-230.

Ruz, J. (2016): «Explorando el futuro, los retos de la democratización en México", Revista del IAPEM, Instituto de Administración Pública del Estado de México, n. ${ }^{\circ} 95$ (septiembre-diciembre de 2016), pp. 103-131.

Senado de la República (2011): «Dictamen de las Comisiones Unidas de Puntos Constitucionales, de Reforma del Estado y de Estudios Legislativos con Proyecto de Decreto que reforma y adiciona diversos artículos de la 
Constitución Política de los Estados Unidos Mexicanos, en materia de reforma política», Gaceta Parlamentaria, LXI/2SPO-254/29507, pp. 1-77.

Tormey, S. (2015): «Democracy will never be the same again: $21^{\text {st }}$ Century Protest and the Transformation of Politics», Recerca, Revista de Pensament i Análisi (17), pp. 107-128.

Torres, G. (2016): «En las elecciones 2016, perdieron los independientes», Milenio, 09-06-2016, [http://www.milenio.com/firmas/gabriel_torres_ espinoza/elecciones-perdieron-independientes_18_753104744.html]

Woldenberg, J. (2012): «Candidaturas ¿independientes?», Nexos, 015, diciembre, [http://www.nexos.com.mx/?p=15117]

ZovatTo, D. (2014): «Las instituciones de la democracia directa», en Democracias en movimiento. Mecanismos de democracia directa y participativa en América Latina. México, Universidad Nacional Autónoma de México, pp. 13- 70. 